\title{
SSR Based Genetic Diversity Analysis in Diploid Algaroba (Prosopis spp.) Population
}

\author{
Lívia S. Freitas ${ }^{1}$, Cláusio A. F. Melo ${ }^{2}$, Fernanda A. Gaiotto ${ }^{2} \&$ Ronan X. Corrêa ${ }^{2}$ \\ ${ }^{1}$ Graduate Program of Genetics and Molecular Biology, State University of Santa Cruz, Ilhéus, Brazil \\ ${ }^{2}$ Department of Biological Sciences, State University of Santa Cruz, Ilhéus, Brazil \\ Correspondence: Ronan X. Corrêa, Department of Biological Sciences, State University of Santa Cruz, Ilhéus, \\ BA, CEP 45662-900, Brazil. Tel: 55-73-3680-5443. E-mail: ronanxc@uesc.br
}

$\begin{array}{ll}\text { Received: September 12, } 2018 & \text { Accepted: October 17, } 2018 \quad \text { Online Published: December 15, } 2018 \\ \text { doi:10.5539/jas.v11n1p179 } & \text { URL: https://doi.org/10.5539/jas.v11n1p179 }\end{array}$

The research is financed by Universidade Estadual de Santa Cruz, Fundação de Amparo à Pesquisa do Estado da Bahia, and Baby Bode Empreendimentos Agropecuários Ltda.

\begin{abstract}
Algaroba (Prosopis palida and Prosopis juliflora species) provides important environmental and economic benefits for semi-arid regions of the world. These are resistant to drought, and its fruits are used in the manufacture of flour and algarobina syrup. In the present study, the chromosome number, the ploidy level, and the genetic diversity based on 40 microsatellite loci of Prosopis spp. were determined in samples of a Brazilian algaroba population. The cytogenetic analysis in the metaphase showed only diploid individuals $(2 n=28)$, with multiple cells featuring two $\mathrm{CMA}^{3} / \mathrm{DAPI}^{-}$heterochromatic blocks suggesting diploid level. However, polysomatism was found by the presence of some cells with four CMA ${ }^{3} /$ DAPI $^{-}$blocks, showing the tetraploid level just in some somatic cells. Among all of the primers tested for cross-amplification in algaroba, 22 were selected to characterize the samples. Thirteen loci revealed allele polymorphisms in the population and are recommended for future population studies and genetic improvement. The mean values of the analyzes showed low genetic diversity (two alleles per locus and $H_{E}=0.181$ ), reflecting the history of the introduction of algaroba in this sampled locality, and suggesting the genetic bottleneck and probable events of founders, as well as the characteristics of the species of this genera. However, amplified loci indicated low inbreeding (allelic fixation index of -0.007), although heterozygosis was higher than expected by the Hardy-Weinberg equilibrium. Therefore, this algaroba population is formed by diploid individuals and adjusts to the tendency of low number of alleles per locus SSR commonly observed in different species of Prosopis.
\end{abstract}

Keywords: cytogenetics, mesquite, algarroba, molecular marker, polysomatism, polyploid, Prosopis juliflora, Prosopis pallida

\section{Introduction}

Prosopis juliflora (Sw.) DC. is known as algaroba in Brazil, and as algarroba or algarrobo in some Spanish-speaking countries, as well as mesquite in African, Asian countries and others. Prosopis juliflora and $P$. pallida (H. \& B. ex. Wild). H.B.K. are legumes, and they form a complex due to taxonomic issues not yet solved (Burkart, 1976; Pasiecznik et al., 2001). The species presents a basic chromosome number of $x=14$, but the variable ploidy level present in most of the sample studies has caused cytotypes to be recognized as tetraploid (Hunziker et al., 1975; Pasiecznik et al., 2001, Nogueira et al., 2007; Trenchard et al., 2008). In this case, variation from $2 n=2 x=28$ to $2 n=4 x=56$ was principally in the genus Prosopis (Trenchard et al., 2008).

The species complex are distributed in Central and South America, Africa, Asia, and Oceania. Algaroba is widely found in the dry forests of Peru and was introduced in Brazil in 1940 (Azevedo, 1955; Burkart, 1976; Pasiecznik et al., 2001). Algaroba is a tropical species and has spread throughout the world for economic reasons and due to its ease of adaptation in arid and semi-arid regions, thus guaranteeing its survival for many centuries. The species is well adapted to regions that suffer periods of severe drought and unproductivity worldwide (Burkart, 1976). The algaroba has the potential to provide a wide range of products in the northeastern part of Brazil, where few useful species are found. It is one of the few economic resources for farmers and inhabitants of 
the region. Algaroba is a food source for animals, an ingredient of breads, flour, sweets, and used as wood, firewood, and coal (Cruz, 1990; Silva, 1996; Felker, 1984; Figueiredo, 2000; Ribaski, 2009).

Considering the value of algaroba, the molecular diversity studies of Prosopis spp. are crucial for understanding the genetics of these invasive plants, their response to adverse conditions and events of genetic drift, and their use in studies on crop's genetic improvement.

Molecular methods for genetic detection of polymorphic microsatellite loci (SSR) can be performed by cross-amplification of markers from related species (Landeras et al., 2006). There are very limited molecular studies for Prosopis spp., and no polymorphic microsatellites were identified to evaluate genetic diversity in Brazilian algaroba populations. Cross-amplification of microsatellite markers was successful between distant taxa (Yasodha et al., 2005). Additionally, the algaroba chromosome number, the existence of species with variation in ploidy, and marker analysis of species with known ploidy will help on determination and evaluation of useful parameters. This phenomenon is commonly observed in plants with high adaptation.

SSR loci were originally developed for $P$. chilensis and $P$. flexuosa (Mottura et al., 2005), P. alba (Torales et al., 2013), P. alba and P. chilensis (Bessega et al., 2013), P. rubriflora and P. ruscifolia (Alves, 2014). Cross-species amplification of six microsatellites markers developed for $P$. chilensis have been tested in seven Prosopis species from Argentina: P. alba, P. caldenia, P. ferox, P. hassleri, P. nigra, P. ruscifolia, P. torquata and $P$. brasiliensis (Mottura et al., 2005). These six SRR loci were also used in cross-application of eight additional Prosopis species: P. tamarugo hybrid, P. pallida, P. juliflora, P. laevigata, P. glandulosa var. torreyana, P. velutina, P. articulata, P. caldenia (Sherry et al., 2011). So, cross-amplification with the six microsatellite loci in 15 different Prosopis species indicates that there must be a high level of similarity of flanking sequences from repetitive sites in Prosopis spp. However, these primers were not genetically characterized at the level of populations of these species; this is a necessary information to plan the use of the loci in population studies. In addition, the number of loci existing for each species is not sufficient for more comprehensive genetic studies in populations. Thus, the cross-amplification of SSR loci available in Prosopis is an alternative to characterize primers aiming studies of algaroba populations.

The genetic aspects of representative algaroba population in the state of Bahia, Brazil, was studied with the following objectives: i) To test the chromosomal number, ploidy level of this selected population to determine the use of chosen molecular markers; ii) To test the cross-amplification of selected simple sequence repeat/microsatellite loci in Prosopis juliflora and P. pallida; iii) To evaluate the polymorphism of the number of alleles per locus, heterozygosity and coefficient of inbreeding; iv) To determine the genetic diversity of the Brazilian algaroba population and to compare this diversity with previous studies of different populations.

\section{Materials and Methods}

\subsection{Study Site and Plant Material}

The samples were collected in a farm located in the municipality of Manoel Vitorino, Bahia, Brazil (Figure 1), in a semi-arid region characterized by the predominance of the Caatinga biome and bordered by the De Contas River. It is an area of the occurrence and cultivation of the Prosopis species for animal feed.

Leaves were collected from 20 representative genotypes of the population, and they were identified, stored, and taken to the Laboratory of the Center for Biotechnology and Genetics (CBG) at the State University of Santa Cruz (UESC) for the development of the molecular marker research. 


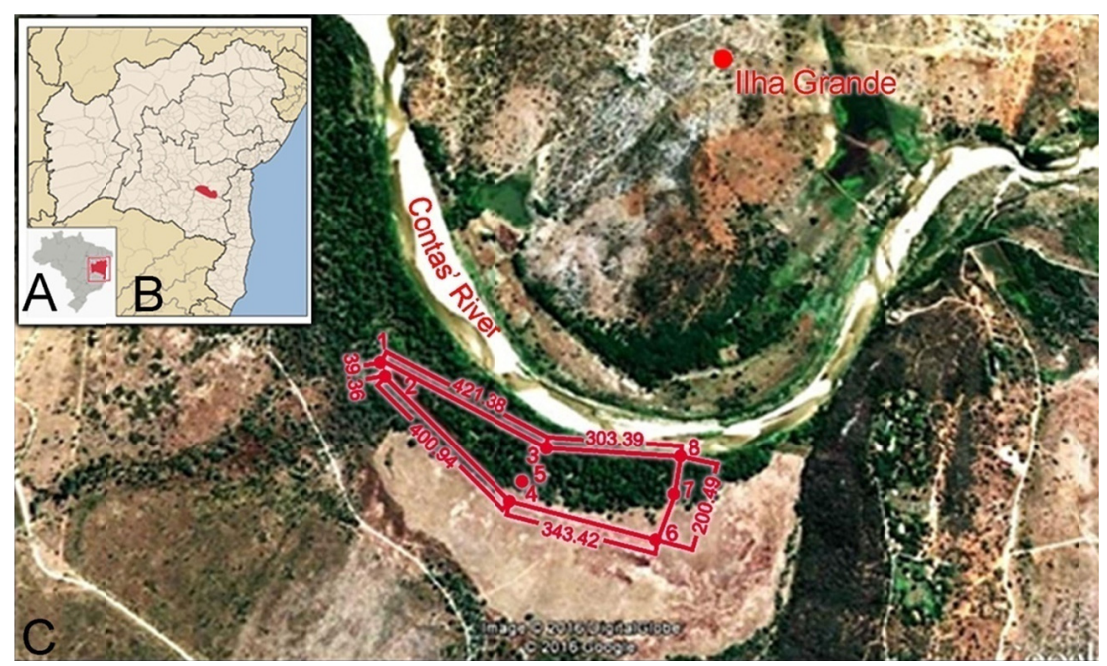

Figure 1. Location of the sampling area of algaroba population. (A) Positioning of Bahia in the Brazil map (red square) and (B) positioning of Manoel Vitorino municipality on the map of Bahia state (red spot). (C) Polygon of the area of algaroba collection, indicating the distances of some points sampled in meters. Number 1 to 8 are collection sites in RIOCON Farms in Contas' River (Source: Google Earth) (Drawing: Romildo Freitas). Collection sites and coordination are: (1) $13^{\circ} 50^{\prime} 28^{\prime \prime} \mathrm{S}, 40^{\circ} 43^{\prime} 29^{\prime \prime} \mathrm{W}$; (2) $13^{\circ} 50^{\prime} 29^{\prime \prime} \mathrm{S}, 40^{\circ} 43^{\prime} 29^{\prime \prime} \mathrm{W}$; (3) $13^{\circ} 50^{\prime} 35^{\prime \prime}$ S, 404'ㄱ' $17^{\prime \prime} \mathrm{W}$; (4) $13^{\circ} 50^{\prime} 39^{\prime \prime} \mathrm{S}, 40^{\circ} 43^{\prime} 20^{\prime \prime} \mathrm{W}$; (5) $13^{\circ} 50^{\prime} 38^{\prime \prime} \mathrm{S}, 40^{\circ} 43^{\prime} 19^{\prime \prime} \mathrm{W}$; (6) $13^{\circ} 50^{\prime} 43^{\prime \prime} \mathrm{S}, 40^{\circ} 43^{\prime} 09^{\prime \prime} \mathrm{W}$; $13^{\circ} 50^{\prime} 40^{\prime \prime} \mathrm{S}, 40^{\circ} 43^{\prime} 08^{\prime \prime} \mathrm{W} ; 13^{\circ} 50^{\prime} 37^{\prime \prime} \mathrm{S}, 40^{\circ} 43^{\prime} 07^{\prime \prime} \mathrm{W}$

\subsection{Determination of the Level of Ploidy by Fluorochrome Banding}

Algaroba's seeds were collected and germinated in Petri dishes with filter paper daily moistened with distillated water until root growth. Radicles were pretreated for $24 \mathrm{~h}$ at $8{ }^{\circ} \mathrm{C}$ with $0.002 \mathrm{~mol} . \mathrm{L}^{-1} 8$-hydroxyquinoline for well spread metaphase obtainment. After pretreatment radicles were fixed in freshly Carnoy 1 fixative [ethanol:acetic acid $(3: 1, \mathrm{v} / \mathrm{v})$ (Johansen, 1940) for $24 \mathrm{~h}$ at room temperature and stored in the freezer $\left(-22{ }^{\circ} \mathrm{C}\right)$ before cytological slide preparation. The cytological slides preparation were performed using radicles digested by cellulase and pectinase $(2: 20 \mathrm{v} / \mathrm{v})$ for $1 \mathrm{~h}$ at $37{ }^{\circ} \mathrm{C}$ followed by squashing in $45 \%$ acetic acid according to Guerra and Souza (2002). Slides were aged for three days before and after the chromosome banding by the use of Cromomycin $\mathrm{A}_{3}\left(\mathrm{CMA}_{3}\right)$ and 4'6-diamidino-2-phenylindole (DAPI) fluorochromes. The banding was performed according to the protocol proposed by Schweizer \& Ambros (1994), adding CMA 3 for $1 \mathrm{~h}$ followed by DAPI for $30 \mathrm{~min}$ with the subsequent slides mounting using Mcllvaine-Glycerol 1:1 (v/v). Slides were analyzed using Olympus CX41 epifluorescence microscope and the best well spread cells were recorded with an Olympus DP25 digital camera.

\subsection{Extraction of Genomic DNA}

Deoxyribonucleic acid (DNA) extraction was performed randomly in four of the 20 foliar samples of algaroba of approximately $200 \mathrm{ng}$ for testing and standardization of the extraction protocol. Among the protocols tested, the selected protocol was Sorbitol/CTAB 2.0\% (Storchová et al., 2000). The DNA extracted from the samples was quantified based on comparative assessments of the observed band standards and the Lambda (standard molecular DNA $\lambda$ ) marker (Invitrogen).

\subsection{Cross-Amplification of Microsatellite Markers}

Cross-amplification was performed using 40 microsatellite or simple sequence repeat (SSR) primers developed for the Prosopis species selected in the literature (Suplementary material). A total of 11 SSR primers from Prosopis alba described by Torales et al. (2013), 23 primers for Prosopis rubriflora and Prosopis ruscifolia by Alves et al. (2014), and six primers for Prosopis chilensis and Prosopis flexuosa by Mottura et al. (2005).

The SSR loci amplifications were done using a final volume of $13 \mu \mathrm{L}$ composed of $3 \mu \mathrm{L}$ of DNA $(2.5 \mathrm{ng} / \mu \mathrm{L})$; $1.3 \mu \mathrm{L}$ of PCR buffer 10X pH 8.5 (Tris-HCl $\left.10 \mathrm{mmol} \mathrm{L}^{-1}, \mathrm{KCl} 50 \mathrm{mmol} \mathrm{L}^{-1}\right) ; 0.39 \mu \mathrm{L}$ of $\mathrm{MgCl}_{2}\left(25 \mathrm{mmol} \mathrm{L}^{-1}\right)$; $0.26 \mu \mathrm{L}$ of dNTP $\left(25 \mathrm{mmol} \mathrm{L}^{-1}\right) ; 1.3 \mu \mathrm{L}$ of BSA $(2.5 \mu \mathrm{g} / \mathrm{mL}) ; 0.26 \mu \mathrm{L}$ of primer $\left(10 \mu \mathrm{mol} \mathrm{L}^{-1}\right) ; 0.52 \mu \mathrm{L}$ of primer labeled with specific fluorochromes $\left(1 \mu \mathrm{mol} \mathrm{L} \mathrm{L}^{-1}\right)$; and $0.2 \mu \mathrm{L}$ of Taq DNA polymerase $(5 \mathrm{U} / \mu \mathrm{L})$ (Phoneutria).

The amplifications were performed with the following PCR program: 30 cycles of $94{ }^{\circ} \mathrm{C}$ for $45 \mathrm{~s}$, specific 
annealing for each primer for $45 \mathrm{~s}, 72{ }^{\circ} \mathrm{C}$ for $45 \mathrm{~s}$; and 10 cycles of $94{ }^{\circ} \mathrm{C}$ for $1 \mathrm{~min}, 53{ }^{\circ} \mathrm{C}$ for $45 \mathrm{~s}, 72{ }^{\circ} \mathrm{C}$ for $45 \mathrm{~s}$, final extension with $72{ }^{\circ} \mathrm{C}$ for $5 \mathrm{~min}$. The amplification products were visualized by GelGreen ${ }^{\mathrm{TM}}$ stained $1 \%$ agarose gel electrophoresis in conjunction with $1 \mathrm{~Kb}$ DNA ladder as standard marker (Invitrogen ${ }^{\circledR}$ ). Genotyping was performed on ABI 3500XL (Applied Biosystems ${ }^{\circledR}$ ) with the aid of GeneMapper ${ }^{\circledR}$ software (Applied Biosystems $^{\circledR}$ ).

The characterization of SSR loci followed the estimation of genetic parameters: the number of alleles per locus $(A)$; observed heterozygosity $\left(H_{O}\right)$; expected heterozygosity $\left(H_{E}\right)$; and inbreeding coefficient $(I)$. These parameters were estimated according to Wright's statistics $(1951,1965)$ in the GenAlEx 6.5 software (Peakall \& Smouse, 2012), which indicates the ability to identify the individual by its genotype (Paetkau et al., 1995), using polymorphic information (PIC); paternity exclusion index (Q) (Kalinowski et al., 2007); and linkage disequilibrium (LD) with Genepop 4.2 software (Rousset, 2008). The Hardy-Weinberg equilibrium (HWE) was also evaluated using the formula $\left(H_{E}-H_{O}\right) / H_{E}$ within population, which was calculated using GenAlEx 6.5 software (Peakall \& Smouse, 2012). The dispersion and clustering of population access was performed by Principal Components Analysis (PCA) in GenAlEx 6.5 software (Peakall \& Smouse, 2012).

The comparative study analysis revealed diversity in the populations by different researchers in the characterization of Prosopis sp using SSR primers. In this analysis, the estimated mean $H_{O}$ and $H_{E}$ parameters of each population used in the SSR characterization developed for Prosopis were obtained as follows: (i) data obtained from previously published articles that presented them in the results (Pomponio et al., 2015); (ii) parameters calculated as the mean of the expected heterozygosity $\left(H_{E}\right)$ and heterozygosity observed $\left(H_{O}\right)$ values of each locus characterized in the previous works (Bessega et al., 2013; Alves et al., 2014); and (iii) original data from this study concerning a Brazilian population.

\section{Results}

\subsection{Ploidy Level and Chromosome Banding}

All analyzed genotypes in our study have the majority of cells with the diploid chromosome number $2 n=28$ (Figure 2). All chromosome counts were performed in very scattered metaphases and no indication of chromosome loss due to mechanical damage. However, some polyploid cells with $2 n=56$ were simultaneously found. This result was confirmed with the presence of some giants nucleus together with the majority of smalls nucleus.

The analysis of the $\mathrm{CMA}_{3}$ and DAPI banding showed that diploids cells $(2 n=28)$ have two $\mathrm{CMA}_{3}{ }^{+} / \mathrm{DAPI}^{-}$ terminal blocks (Figure $2 \mathrm{~A}$ ). However, four $\mathrm{CMA}_{3}{ }^{+} / \mathrm{DAPI}^{-}$terminal blocks were found in few amount of polyploidy cells with $2 n=56$ chromosome (Figure $2 \mathrm{~B}$ ). In some cases, the $\mathrm{CMA}_{3}{ }^{+} / \mathrm{DAPI}$ blocks were distanced from the chromosomes, but it can be clearly observed by photo overlaps. The number of $\mathrm{CMA}_{3}^{+} / \mathrm{DAPI}^{-}$blocks was confirmed by the number of $\mathrm{CMA}_{3}{ }^{+}$blocks on interphasic nucleus.
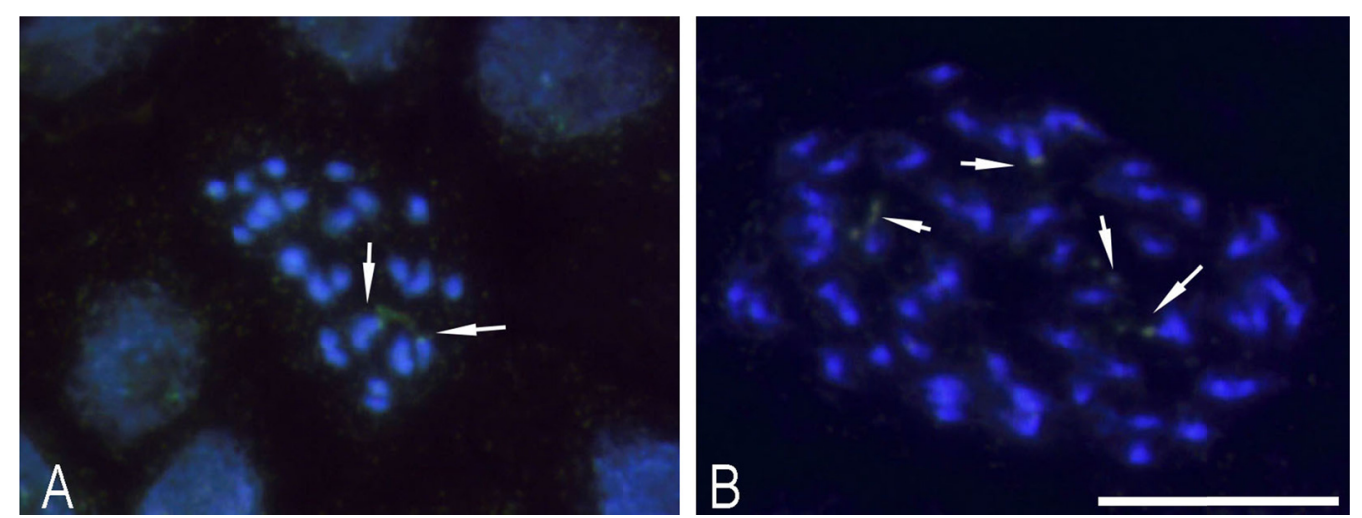

Figure 2. Metaphases of the algaroba complex. (A) overlap $\mathrm{CMA}_{3}{ }^{+} / \mathrm{DAPI}^{-}$in diploid cell. (B) Overlapping $\mathrm{CMA}_{3}{ }^{+} / \mathrm{DAPI}^{-}$in polyploid cell. Arrows indicate $\mathrm{CMA}_{3}{ }^{+} / \mathrm{DAPI}^{-}$blocks related to secondary constrictions and satellites. Bar $=10 \mu \mathrm{m}$

\subsection{Cross-Species Amplification of SSR}

The source of the SSR primers used in the cross-amplification test to algaroba are five Prosopis species of 
natural populations concentrated in arid, semi-arid (P. alba, P. chilensis, and P. flexuosa), and subtropical ( $P$. ruscifolia and $P$. rubriflora) regions of South America.

Among the 40 primers tested, 34 (85\%) were cross-amplified. However, only 22 primers were selected as a functional with ideal minimum size of 100 base pair (bp) fragment for genotyping, excluding the possibility of false allele interpretations in reading the peaks (Table 1). Of these amplified primers, at least one allele per locus was verified. Amplicons in the $176 \mathrm{bp}$ and $371 \mathrm{bp}$ range were detected. The amplification temperature of most of the primers (16) was at $56{ }^{\circ} \mathrm{C}$, and the others required specific temperatures of $52{ }^{\circ} \mathrm{C}$ to $58{ }^{\circ} \mathrm{C}$.

Table 1. SSR primers derived from Prosopis species cross-amplified to algaroba complex with allele amplitude and optimized hybridization temperature

\begin{tabular}{lllll}
\hline Locus & Forward 5'-3' sequence & Reverse 5'-3' sequence & Amplicon & TM ${ }^{\mathbf{}} \mathbf{C}$ \\
\hline I-P06286b & TGACAACCCATCTTCTTCTTCA & ATTTGCACAAGGGTAAAGATGG & $176-246$ & 52 \\
I-P06639 & CATCCCGTTCAAGTCCAAGT & AGCCCCTTCCAACTTCTAA & $184-260$ & 57 \\
I-P10500 & CTCCGACAGATTCAGCATCA & TTCTTTCAAACTCGCCATCA & $230-305$ & 56 \\
I-P07653 & AGTGATGATTCGGATCCTGG & GAGAGACGAGGACTTGGTGC & $136-250$ & 56 \\
I-P00930d & TCGAGATTTCTTGGGGTTG & AAATTCCCTCCTCCTCCAAA & $146-208$ & 56 \\
I-P00930c & TATGGCGCTATTTTTGGAGG & TCATGCTCCTCACAATCTGC & $206-270$ & 56 \\
I-P00930b & GCAACAGCACTGCTTCAAA & AAAATAGCGCCATAGTTGCTC & $230-298$ & 56 \\
S-P1DKSFA & GTTTACCCATTGCAGGTCGT & CCCCATATGCAGAATCACCT & $132-193$ & 55 \\
I-P03211 & TTGCTTCAGAAAGCTGCTCA & AACCCTCGAAGATGATGGTG & $160-229$ & 56 \\
Mo05 & AATTCTGCAGTCTCTTCGCC & GATCCCTCGTGACTCCTCAG & $184-248$ & 56 \\
Mo07 & GAAGCTCCCTCACATTTTGC & CTATTTGCGCAACACACAGC & $155-243$ & 56 \\
Mo08 & TATCCTAAACGCCGGGCTAC & TCCCATTCATGCATACTTAAACC & $174-252$ & 56 \\
Mo09 & ATTCCTCCCTCACATTTTGC & CATTATGCCAGCCTTTGTTG & $173-275$ & 56 \\
Prb9 & TTCTTCTCCTTCTTCATCTTCCTCC & ACAACGTTGATCCCAAAACCTAAG & $137-205$ & 56 \\
Prsc1 & AATGGAGTTTGTTTGTTCTGTGG & ATTACGGATACATCGAGCCTTCTT & $243-327$ & 56 \\
Prsc3 & CCACAAGCACACGCACACTCAGAC & CCAGCACTAGACTTCGCCACCAAC & $126-190$ & 58 \\
Prsc4 & CAAAATCCAACAAATAAACACACC & GGCGGATTCTTGGCTCTCT & $188-262$ & 57 \\
Prsc5 & CGCGTTAAGTCTGCCTTGCTTT & CTCATGGTATTTCCCTTGTCGTCC & $190-270$ \\
Prsc6 & CGAGCGGCGAAAAATGATAAA & GCTGCTTCCCATAATCCTCTCCT & $154-240$ \\
Prsc10 & AACGCAACGGCCGCAACTAT & ACAAAACGCTCGAATACTGGGGG & $230-314$ \\
Prsc11 & CCCGGCAACTCAAATCAACTTCATA & GTCTAATTCTATTGGTGGGCTCTCTGG & $199-421$ & 56 \\
Prsc12 & GGGGTGCATGTTGGGGATTG & TTTGGCCGGATTAAAACAGAGCA & $155-253$ & 56
\end{tabular}

\subsection{Genetic Characterization of SSR Loci}

The genetic data analysis in 20 algaroba genotypes for polymorphic loci is described (Table 2). Among 22 primers, 13 amplified more than one allele, four of which were the maximum number of alleles found per locus, and a total of 46 alleles were distributed among the 20 accessions of the algaroba. The loci showed a mean $H_{O}$ that was greater than the $H_{E}$, and the mean of the PIC was 0.167 , having values lower than or similar to those of the species to which the loci were developed. 
Table 2. Descriptive genetics of microsatellites analyzed in algaroba

\begin{tabular}{|c|c|c|c|c|c|c|c|}
\hline Locus & $\mathbf{N}$ & $\mathbf{A}$ & $\boldsymbol{H}_{\boldsymbol{O}}$ & $\boldsymbol{H}_{E}$ & PIC & HWE & $F$ \\
\hline I-P06286b-A & 20 & 1 & 0.000 & 0.000 & 0.000 & NS & - \\
\hline I-P06639-A & 20 & 1 & 0.000 & 0.000 & 0.000 & NS & - \\
\hline I - P10500-A & 20 & 1 & 0.000 & 0.000 & 0.000 & NS & - \\
\hline I-P07653-A & 20 & 1 & 0.000 & 0.000 & 0.000 & NS & - \\
\hline I-P00930d-A & 20 & 1 & 0.000 & 0.000 & 0.000 & NS & - \\
\hline I-P00930c-A & 20 & 3 & 0.650 & 0.454 & 0.371 & NS & -0.433 \\
\hline I-P00930b-A & 20 & 2 & 0.050 & 0.049 & 0.048 & NS & -0.026 \\
\hline S-P1DKSFA-A & 20 & 1 & 0.000 & 0.000 & 0.000 & NS & - \\
\hline I-P03211-A & 20 & 3 & 0.950 & 0.524 & 0.410 & $*$ & -0.814 \\
\hline Mo05-A & 20 & 4 & 0.200 & 0.269 & 0.256 & NS & 0.256 \\
\hline Mo07-A & 20 & 3 & 0.450 & 0.366 & 0.326 & NS & -0.229 \\
\hline Mo08-A & 20 & 1 & 0.000 & 0.000 & 0.000 & NS & - \\
\hline Mo09-A & 20 & 2 & 0.000 & 0.095 & 0.090 & NS & 1.000 \\
\hline Prb9-A & 20 & 1 & 0.000 & 0.000 & 0.000 & NS & - \\
\hline Prsc1-A & 20 & 3 & 0.400 & 0.516 & 0.406 & NS & 0.225 \\
\hline Prsc3-A & 20 & 2 & 0.050 & 0.049 & 0.048 & NS & -0.026 \\
\hline Prsc4-A & 20 & 3 & 1.000 & 0.524 & 0.410 & $* *$ & -0.909 \\
\hline Prsc5-A & 20 & 2 & 0.200 & 0.320 & 0.269 & NS & 0.375 \\
\hline Prsc6-A & 20 & 3 & 0.050 & 0.096 & 0.094 & NS & 0.481 \\
\hline Prsc10-A & 18 & 3 & 0.222 & 0.204 & 0.194 & NS & -0.091 \\
\hline Prsc11-A & 20 & 3 & 0.100 & 0.096 & 0.094 & NS & -0.039 \\
\hline Prsc12-A & 8 & 2 & 0.375 & 0.430 & 0.337 & NS & 0.127 \\
\hline Total & - & 46 & & & & & \\
\hline Mean & - & 2.09 & 0.214 & 0.181 & 0.167 & - & -0.007 \\
\hline
\end{tabular}

Note. $\mathrm{N}=$ number of individuals with cross-amplified loci; $\mathrm{A}=$ number of alleles; $\mathrm{PIC}=$ informative content of polymorphism; $H_{O}=$ observed heterozygosity; $H_{E}=$ expected heterozygosity; HWE = Hardy-Weinberg equilibrium; $F=$ inbreeding. NS $=$ non-significant deviation $* \mathrm{p}<0.05 * * \mathrm{p}<0.01$.

The mean for the combined exclusion of the loci $(\mathrm{Q})$ was 0.96 , and the coefficient of identity $(I)$ estimate was 0.00022963 .

In the analysis of linkage disequilibrium, no non-random association was found for the great majority of pairs of microsatellite loci, and loci with only one allele were not computed. The associated pairs were (Mo07, Prsc5), (Prsc5, Prsc10), and (Prsc1, Prsc11).

\subsection{Grouping of Individuals in the Population}

In the analysis of the main components, three groups were observed: one group with eight individuals, one group with 11 individuals, and another with just one individual (Figure 3).

\subsection{Characteristics of Markers}

In the analysis of the genetic diversity of different populations of the genus of Prosopis characterized by the microsatellite loci of several studies previously established in the literature, it can be observed that the mean values of $H_{O}$ and $H_{E}$ of all populations were intermediate or low (Table 3 ). 


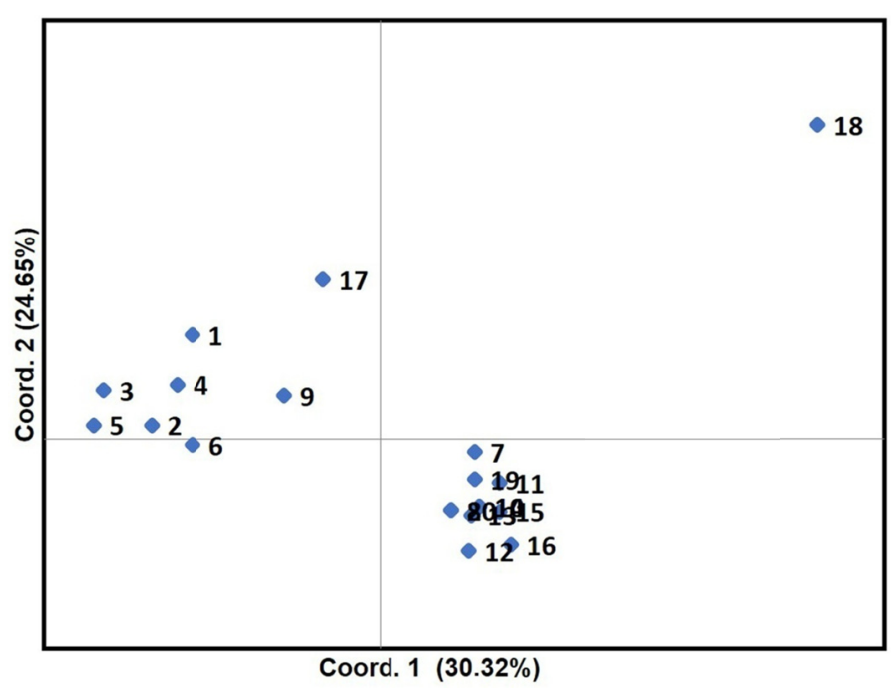

Figure 3. Dispersion of 20 algaroba individuals according to principal component analysis (PCA) based on genetic distance matrix calculated on the basis of microsatellite markers

Tabele 3. Mean values of $H_{O}$ and $H_{E}$ estimates of different populations of Prosopis spp.

\begin{tabular}{llllll}
\hline Species & $\mathrm{N}$ & $H_{O}$ & $H_{E}$ & Pop & Source \\
\hline Algaroba & 13 & 0.214 & 0.181 & CC & Data of this study \\
P. alba & 11 & 0.366 & 0.414 & PN & Pomponio et al., 2015 \\
P. flexuosa & 7 & 0.286 & 0.354 & PN & Pomponio et al., 2015 \\
Híbridos & 8 & 0.286 & 0.344 & PN & Pomponio et al., 2015 \\
$P$. chilensis & 8 & 0.310 & 0.319 & PN & Pomponio et al., 2015 \\
$P$. denudans & 6 & 0.357 & 0.421 & PN & Pomponio et al., 2015 \\
P. hassleri & 10 & 0.300 & 0.333 & PN & Pomponio et al., 2015 \\
P. rubriflora & 8 & 0.545 & 0.592 & FSM & Alves et al., 2014 \\
$P$. rubriflora & 9 & 0.463 & 0.529 & FSV & Alves et al., 2014 \\
$P$. ruscifolia & 12 & 0.390 & 0.537 & FRC & Alves et al., 2014 \\
$P$. ruscifolia & 12 & 0.418 & 0.687 & ECD & Alves et al., 2014 \\
$P$. alba & 12 & 0.570 & 0.595 & PN & Bessega et al., 2013 \\
$P$. chilensis & 8 & 0.607 & 0.647 & PN & Bessega et al., 2013 \\
$P$. flexuosa & 6 & 0.486 & 0.725 & PN & Mottura et al., 2005 \\
$P$. chilensis & 6 & 0.525 & 0.508 & PN & Mottura et al., 2005
\end{tabular}

Note. $\mathrm{N}=$ Number of loci used. $\mathrm{CC}=$ Commercial cultivation. $\mathrm{PN}=$ Natural population. FSM and FSV $=$ (Fazenda Retiro Conceição) remaining areas of the Chaco region in Brazil. ECD = (Estação do Carandazal) remnant population highly anthropized. FRC $=$ area recovered from a 15-year depression on a farm. Obs. In Pomponio et al. (2015), we did not consider loci with zero value in the calculation of $H_{O}$ and $H_{E}$.

\section{Discussion}

In the present study, the chromosome number and diversity and genetic variability in microsatellite loci were evaluated in a Brazilian algaroba population. Our experimental data demonstrated that this population is formed by diploid individuals, which have polysomatism events, and present microsatellite loci with low polymorphism. Additionally, the analysis were based on the evaluation of algaroba diversity in combination with the allele diversity data in the literature, confirming the hypothesis regarding a low diversity of alleles in SSR loci as a common route in Prosopis species.

The level of polyploid of algaroba has been investigated using both chromosome count (Nogueira et al., 2007) and flow cytometry (Trenchard et al., 2008). However, the identification of chromosomal markers such as $\mathrm{CMA}_{3}{ }^{+}$blocks and other cytological markers may contribute to the discovery of polyploid species and/or cytotypes by the multiplicity of these markers compared to diploid genotypes (Melo et al., 2014, 2017). The chromosomes of algaroba could be better analyzed by the application of the base-specific fluorochromes $\mathrm{CMA}_{3}$ 
and DAPI, which facilitated the visualization and definition of the chromosome due to its small size, in comparing to Giemsa staining in our previous studies.

In the genus Prosopis the most common chromosome number found has been $2 \mathrm{n}=28$, based on the basic number $\mathrm{x}=14$ we can consider these diploid species. However, the $P$. juliflora taxon, found naturally in both North and South America, has been shown to be tetraploid with $2 \mathrm{n}=4 \mathrm{x}=56$ (Trenchard et al., 2008). However, in Brazil, algaroba can present both diploid and polyploid cytotypes (Hunziker et al., 1975). It also corroborates the findings of Nogueira et al. (2007), which analyzed a population of $P$. juliflora from three municipalities of different Brazilian states. Only one of the accessions sampled in one of the populations was found in the tetraploid form while the others were diploids. Therefore, although the algaroba population analyzed in the present study is considered locally as P. juliflora, this population should be P. pallida.

The occurrence of polysomatism in the species consisting of cells or organs of the same individual with levels of ploidy was verified. Barow (2006) reports that polysomatism is common in well-adapted plants and is important for accelerated plant growth, as well as to support certain physiological cellular functions. This event differs from polyploidy, which consists of the entirety of the individual's cells having extra chromosome sets. The erroneous interpretations of polyploidy for $P$. juliflora have been explained by the polysomatism that commonly occurs in root tissues that are used in analyses, or even by non-accurate counting errors (Burkart, 1976). Additionally, the low frequency with which tetraploid cells are reported in the literature could be understood as possible polysomatism and not necessarily the appearance of polyploid individuals. Specifically, in relation to the results obtained in the present study, it has been proven to be a case of polysomatism.

Prosopis juliflora polyploidy origin is still unknown (Pasiecznik, 2001). Trenchard et al. (2008) found only tetraploid individuals for this species from different source, indicating that $P$. juliflora would be the only tetraploid specie related, whereas P. pallida and several other species of Prosopis would be diploid, since 32 species from the genera has been cytological analyzed. However, the algaroba population evaluated in the present study, known among those who cultivate $P$. juliflora, is a true diploid, with rare polysomatism. Introductions of $P$. pallida were made in Brazil, but there were no records or information on the places of these introductions (Burkart, 1976). This divergence proves the taxonomic complexity of the group, and even though there were errors of identification in the native populations of Peru and the Pacific coast. These data suggest the need for future taxonomic, cytogenetic, and phylogenetic studies from their native scale that can clarify both the history and the identification of consensus for these Prosopis materials in Brazil.

Our analyses using molecular markers revealed that loci I-P03211 and Prsc4 showed a deviation to the proportions expected by the Hardy-Weinberg equilibrium considering the $95 \%$ and $99 \%$ confidence interval, respectively. This result is due to the number of heterozygotes observed to be much higher than expected.

Despite the low allelic diversity, the average inbreeding coefficient or loss of heterozygotes $(F)$ was considered to be optimal because the population presented a low level of heterozygosity $(-0.007)$. On the other hand, the means for the combined exclusion of the loci $(\mathrm{Q})$ and the estimation of the coefficient of identity $(I)$ were low.

The 13 amplified loci with more than one allele are useful tools for future population and genetic diversity studies of algaroba, although they are not recommended for studies aimed at plant identification and protection due to the low values of the "Q" and "I" indices.

The microsatellite loci "Mo05" developed by Mottura et al. (2005) for P. chilensis and P. flexuosa detected more alleles in the algaroba, to which it was cross-amplified, than in the species to which it was developed. In addition, the same series of loci (Mo05, Mo07, Mo08, Mo09, Mo13, and Mo16) developed by Mottura et al. (2005) were cross-amplified in six other Prosopis species (P. alba, P. caldenia, P. ferox, P. hassleri, P. nigra, P. ruscifolia, and $P$. torquata) and the range of alleles found from zero to five, was very similar to that of our algarroba population that ranged from zero to four alleles per locus. Similarly, the loci developed by Alves et al. (2014) for $P$. ruscifolia and P. rubriflora detected between one and five alleles per locus, and only one locus (Prb9) of $P$. rubriflora amplified to algaroba with just one allele, probably due of the genetic distance between them. In a study carried out by Bessega et al. (2013), microsatellite loci developed for P. alba and P. chilensis also obtained a higher concentration between two and five alleles per locus. These loci were not used in this work for algaroba.

Although the loci developed by Torales et al. (2013) for P. alba have amplified algaroba DNA of the species tested, these loci did not show data of allelic diversity. Thus, the reduced number of alleles detected in the present study is explained by the low allelic diversity of the species of the genus Prosopis.

Despite the low allelic diversity, low inbreeding levels were found even in the phase of the introduction, history of the species, with possible genetic bottleneck events and founder effects. This fact can be explained on the 
basis of two hypotheses. The first one is related to the fact that the "F" evaluates the result of the crossings of individuals from one generation to another; thus, this indicates that there was no intersection between relatives in the previous generation. The second hypothesis that can have a joint action with the first is the reproductive system of the species that favors heterozygosis, because it is allogamous and self-incompatible.

As for the associated pairs in the analysis of linkage disequilibrium, we suggest the use of $\mathrm{X}, \mathrm{Y}$, and $\mathrm{Z}$ only because they contain a higher ICP or because they have a greater number of alleles.

The data of the grouping of the individuals evidences the dispersion of the accessions sampled by the genetic distance. Of the three groups, one has individuals that were more closely connected, indicating the possibility of having origins of the same region in cases of cultivated individuals or of individuals those have been naturally dispersed by the region. It is possible that these individuals may be the fruit of crossing individuals that are physically close and the other groups otherwise. Despite the genetic distance shown in the analysis, the 18 followed the same pattern of the other accessions collected.

The results of this study add value to the literature, showing the importance of having molecular tools from species with a close phylogenetic relationship, because the algaroba ( $P$. juliflora- $P$. pallida) has no SSR developed and the present work contributed 22 cross-amplified SSR loci.

The results of the diversity of the different populations of Prosopis may be related to the low number of alleles found in the Prosopis species, for which molecular data are known. Another observation is that, among these species, only the population used in the present study presented an estimate of $H_{O}$ higher than that of $H_{E}$. Because the area sampled in the present study is a growing area, introductions of different accessions may have favored the observed heterozygosity, even with low allelic diversity.

In addition to our comparison with the literature, we added new genotyping data of a Brazilian population of algaroba. However, there are populations of algaroba in different states of northeastern Brazil. Therefore, the following question remains open for future investigation: are the different Brazilian populations formed by diploid individuals? Do these populations have the general tendency of low polymorphism in SSR loci? There were multiple introductions of algaroba in Brazil? The microsatellite loci that showed cross-amplification and PIC in algaroba in the present work are useful to delineate new studies aimed to answer these questions.

Although the different studies carried out at distinct areas such as natural populations, anthropic areas and recovered areas, there was no correlation pattern with $H_{O}$ values. The natural population of $P$. chilensis showed the highest mean value of $H_{O}(0.607)$ of the presented studies, however it was lower than the mean $H_{E}$ value (0.647). This information reinforcing that the low genetic diversity is not strictly related to the environmental conditions of the study area, but with a natural characteristic of the genus.

\section{Acknowledgements}

The authors thank Baby Bode Empreendimentos Agropecuários Ltda and Fundação de Amparo à Pesquisa do Estado da Bahia for financial support in plant collection. LSF and CAFM received scholarships from Coordenação de Aperfeiçoamento de Pessoal de Nivel Superior. RXC and FAG received a fellowship of scientific productivity from Conselho Nacional de Ciência e Tecnologia. We are grateful to Mauricio Pita de Melo and Renan Silva Ferreira for technical support in collecting plants in the RIOCON-Fazendas Reunidas Rio de Contas Ltda.

\section{References}

Alves, F. M., Zucchi, M. I., Azevedo-Tozzi, A. M., Sartori, Â. L., \& Souza, A. P. (2014). Characterization of microsatellite markers developed from Prosopis rubriflora and Prosopis ruscifolia (LeguminosaeMimosoideae), legume species that are used as models for genetic diversity studies in Chaquenian areas under anthropization in South America. BMC Research Notes, 7, 375. https://doi.org/10.1186/1756-0500$7-375$

Azevedo, G. (1955). "Algaroba" Natal (p. 13). Ministério da Agricultura, Serviço do Acordo do Fomento da Produção Animal.

Bessega, C. F., Pometti, C. L., Miller, J. T., Watts, R., Saidman, B. O., \& Vilardi, J. C. (2013). New microsatellite loci for Prosopis alba and P. chilensis (Fabaceae). Applications in Plant Sciences, 1(5). https://doi.org/10.3732/apps.1200324

Burkart, A. (1976). A monograph of the genus Prosopis (Leguminosae subfam Mimosoidae). Journal Arnold Arboretum. Harv. Univ., 57, 219-249, 450-525.

Cruz, G. E. (1990). Evaluation of flour from Prosopis juliflora and Prosopis pallida pods in bakery and 
extrusion-cooking products. In M. A. Habit, \& J. C. Saavedra (Eds.), The Current State of Knowledge on Prosopis juliflora (pp. 425-439). FAO, Rome, Italy.

Felker, P. (1984). Legume trees in semi-arid and arid areas. Pesquisa Agropecuária Brasileira, 19, 47-59.

Figueiredo, A. A. (2000). Algaroba tecnologia, produtos e usos: Meio século no Brasil. Rio de Janeiro, Brazil, Editora UFRJ.

Guerra, M., \& Souza, M. J. (2002). Como observar cromossomos: Um guia de técnicas em citogenética vegetal animal e humana (1st ed., p. 131). FUNPEC, Ribeirão Preto.

Hunziker, J. H., Poggio, L., Naranjo, C. A., \& Palacios, R. A. (1975). Cytogenetics of some species and natural hybrids in Prosopis (Leguminosae). Canadian Journal of Genetics and Cytology, 17(2), 253-262. https://doi.org/10.1139/g75-033

Johansen, D. A. (1940). Plant microtechnique. Mc Graw Hill, New York.

Kalinowski, S. T., Taper, M. L., \& Marshal, T. C. (2007). Revising how the computer program CERVUS accommodates genotyping error increases success in paternity assignmet. Molecular Ecology, 16(5), 1099-1106. https://doi.org/10.1111/j.1365-294X.2007.03089.x

Landeras, G., Alfonso, M., Pasiecznik, N. M., Harris, P. J. C., \& Ramírez, L. (2006). Identification of Prosopis juliflora and Prosopis pallida Accessions Using Molecular Markers. Biodiversity \& Conservation, 15(5), 1829-1844. https://doi.org/10.1007/s10531-004-6682-5

Melo, C. A. F., Souza, M. M., \& Silva, G. S. (2017). Karyotype analysis by FISH and GISH techniques on artificial backcrossed interspecific hybrids involving Passiflora sublanceolata (Killip) MacDougal (Passifloraceae). Euphytica, 213, 160.

Melo, C. A. F., Souza, M. M., Abreu, P. P., \& Viana, A. J. C. (2014). Karyomorphology and GC-rich heterochromatin pattener in Passiflora (Passifloraceae) wild species from Decaloba and Passiflora subgenera. Flora (Jena), 11, 620-631. https://doi.org/10.1016/j.flora.2014.08.009

Mottura, M. C., Finkeldey, R., Verga, A. R., \& Gailing, O. (2005). Development and characterization of microsatellite markers for Prosopis chilensis and Prosopis flexuosa and cross-species amplification. Molecular Ecology Resources, 5(3), 487-489. https://doi.org/10.1111/j.1471-8286.2005.00965.x

Nogueira, N., Bortoleti, F. M. O., Oliveira, K. C. de A., Drumond, V. R. de, Santos, M. A., \& Melo, C. A. F. (2007). Caracterização citogenética de acessos de algaroba coletados no Semi-Árido Brasileiro. Anais. Petrolina: Embrapa Semi-Árido.

Paetkau, D., Calvert, W., Stirling, I., \& Strobeck, C. (1995). Structure in Canadian polar bears. Molecular Ecology, 4, 347-354. https://doi.org/10.1111/j.1365-294X.1995.tb00227.x

Pasiecznik, N. M., Felker, P., Harris, P. J. C., Harsh, L. N., Cruz, G., Tewari, J. C., Cadoret, K., \& Maldonado, L. J. (2001). The Prosopisjuliflora-Prosopispallida complex: A Monograph. Henry Doubleday, Research Association (HDRA), Coventry, UK.

Peakall, R., \& Smouse, P. (2012). GenAlEx 6.5: Genetic analysis in Excel. Population genetic software for teaching and research - An update (Vol. 1, pp. 6-8).

Pomponio, M. F., Acuna, C., Pentreath, V., Lauenstein, D. L., Poltri, S. M., \& Torales, S. (2015). Characterization of functional SSR markers in Prosopis alba and their transferability across Prosopis species. Forest Systems, 24(2), 4. https://doi.org/10.5424/fs/2015242-07188

Ribaski, J., Drumond, M. A., Oliveira, V. R., Nascimento, C. E. de S. (2009). Algaroba (Prosopis juliflora): Árvore de uso múltiplo para a região Semiárida Brasileira. Embrapa Florestas, Comunicado Técnico, 240. Colombo, Sri Lanka.

Rousset, F. (2008). GENEPOP '007: A complete re-implementation of the GENEPOP software for Windows and Linux. Molecular Ecology Resources, 8(1), 103-106. https://doi.org/10.1111/j.1471-8286.2007.01931.x

Silva, J. I. (1996). Prosopis juliflora as an alternative source of food in the world's semiarid areas. In P. Felker, \& J. Moss (Eds.), Prosopis: Semiarid Fuelwood and Forage Tree; Building Consensus for the Disenfranchised (pp. 319-3241). Center for Semi-Arid Forest Resources, Kingsville, Texas, USA.

Schweizer, D., \& Ambros, P. F. (1994). Chromosome banding: Stain combinations for specific regions. In J. R. Gosden (Ed.), Methods in molecular biology: Chromosome analysis protocols (Vol. 29, pp. 97-112). https://doi.org/10.1385/0-89603-289-2:97 
Sherry, M., Smith, S., Patel, A., Harris, P., Hand, P., Trenchard, L., \& Henderson, J. (2011). RAPD and microsatellite transferability studies in selected species of Prosopis (section Algarobia) with emphasis on Prosopis juliflora and P. pallida. Journal of Genetics, 90, 251-264. https://doi.org/10.1007/s12041-0110068-8

Storchová, H., Hrdličková, R., Chrtek, J. Jr., Tetera, M., Fitze, D., \& Fehrer, J. (2000). An improved method of DNA isolation from plants collected in the field and conserved in saturated NaCl/CTAB solution. Taxon, 49, 79-84. https://doi.org/10.2307/1223934

Torales, S. L., Rivarola, M., Pomponio, M. F., Gonzalez, S., Acuña, C. V., Fernandez, \& Poltri, S. N. (2013). De novo assembly and characterization of leaf transcriptome for the development of functional molecular markers of the extremophile multipurpose tree species Prosopis alba. BMC Genomics, $14,705$. https://doi.org/10.1186/1471-2164-14-705

Trenchard, L. J., Harris, P. J. C., Smith, S. J., \& Pasiecznik, N. M. (2008). A Review of Ploidy in the Genus Prosopis (Leguminosae). Botanical Journal of the Linnean Society, 156(3), 425-438. https://doi.org/ 10.1111/j.1095-8339.2007.00712.x

Wright, S. (1951). The genetical structure of populations. Annals of Eugenetics, 15, 322-354.

Wright, S. (1965). The interpretation of population structure by F-statistics with special regard to systems of mating. Evolution, 19(3), 395-420. https://doi.org/10.2307/2406450

Yasodha, R., Ghosh, M., Sumathi, R., \& Gurumurthi, K. (2005). Cross-species amplification of eucalyptus SSR markers in Casuarinaceae. Acta Botanica Croatica, 64(1), 115-120. 


\section{Appendix A}

Characteristics of the 40 SSR primers obtained in the literature of different species of Prosopis for cross-amplification in algaroba DNA

\begin{tabular}{|c|c|c|c|c|c|}
\hline $\mathrm{N}$ & Locus & Forward 5'-3' sequence & Reverse 5'-3' sequence & TM & Motif \\
\hline 1 & I-P06286b & TGACAACCCATCTTCTTCTTCA & ATTTGCACAAGGGTAAAGATGG & - & (TC) 5 \\
\hline 2 & I-P03325a & CGTGCATGAATGTCACAGAC & AGGGTGAGATCAGAAGGCAA & - & $(\mathrm{CA}) 5$ \\
\hline 3 & I-P06639 & CATCCCGTTCAAGTCCAAGT & AGCCСССТTCCAACTTCTAA & - & $(\mathrm{AT}) 5$ \\
\hline 4 & I-P10500 & CTCCGACAGATTCAGCATCA & TTCTTTCAAACTCGCCATCA & - & (TTC) 6 \\
\hline 5 & I-P07653 & AGTGATGATTCGGATCCTGG & GAGAGACGAGGACTTGGTGC & - & (GTT)4 \\
\hline 6 & I-P00930d & TCGAGATTTTCTTGGGGTTG & AАAТTСССТССТССТССАAА & - & $(\mathrm{AAC}) 6$ \\
\hline 7 & I-P00930c & TATGGCGCTATTTTTGGAGG & TCATGCTCCTCACAATCTGC & - & (GTC)4 \\
\hline 8 & I-P00930b & GCAACAGCACTGCTTCAAA & AAAATAGCGCCATAGTTTGCTC & - & $(\mathrm{ACC}) 5$ \\
\hline 9 & S-P1DKSFA & GTTTACCCATTGCAGGTCGT & CCCCATATGCAGAATCACCT & - & (TTTA)3 \\
\hline 10 & S-P1EPIV2 & TAAGCATTCATAGCCAGCCC & GACCAGGTCCTGTTTACCGA & - & $(\mathrm{TAA}) 4$ \\
\hline 11 & I-P03211 & TTGCTTCAGAAAGCTGCTCA & AACCCTCGAAGATGATGGTG & - & $(\mathrm{AAT}) 4$ \\
\hline 12 & Mo05 & AATTCTGCAGTCTCTTCGCC & GATCCCTCGTGACTCCTCAG & 64 & $(\mathrm{CT}) 3 \mathrm{~T}(\mathrm{CT}) 2$ \\
\hline 13 & $\mathrm{Mo} 07$ & GAAGCTCCCTCACATTTTGC & CTATTTGCGCAACACACAGC & 59 & (GC) 8 \\
\hline 14 & $\mathrm{Mo08}$ & TATCCTAAACGCCGGGCTAC & TCCCATTCATGCATACTTAAACC & 59 & $(\mathrm{AC}) 9$ \\
\hline 15 & Mo09 & ATTCCTCCCTCACATTTTGC & CATTATGCCAGCCTTTGTTG & 59 & (TG)17 \\
\hline 16 & Mo13 & TTGATTAGAGTTGCATGTGGATG & TGCAGTCCCAAGTGTCAGAG & 58 & $(\mathrm{GT}) 10 \mathrm{CT}(\mathrm{GT}) 2$ \\
\hline 17 & Mo16 & CATTGCCCCAATATCACTCC & GGGTCCATCCAGAGTAGTGG & 60 & (CA) 12 \\
\hline 18 & Prb1 & AACTACCGCAGCACTTTTCAGA & ACTACTTGGAGATGCCGTGGA & 62.7 & $(\mathrm{GT}) 7$ \\
\hline 19 & Prb2 & GAAAGCCGCGCTCCTAAG & ATTCTTTTGTGTCTTGTCTTCTCG & 61 & $(\mathrm{GC}) 4(\mathrm{AC}) 7$ \\
\hline 20 & Prb3 & TCCAAAGACCGCAAGAAGAT & AGGCCAAAAAGGACTCAAAAT & 61 & $(\mathrm{CA}) 7$ \\
\hline 21 & Prb4 & ATCCGATAAATACACCTTCTGG & GGTGTATCGTAAAAGCCTGG & 61 & $(\mathrm{CA}) 8$ \\
\hline 22 & Prb5 & TTTAAACATTGCACGTGAACCTAT & ТTCAССССТАААСССССТТ & 56.4 & $(\mathrm{AC}) 9$ \\
\hline 23 & Prb6 & CATCTCTCAAAGAAAACGCACTC & CCGCAGAGAAGCCCCTACATA & 56.4 & (TG) 10 \\
\hline 24 & Prb7 & GGCTTAGCATCACCCTCCAT & CTTACCСТTTCAGTCCATTTACCA & 61 & $(\mathrm{AC}) 8$ \\
\hline 25 & Prb8 & CAACACCAAAACGGCGAGATGAT & TTCGCCAAACGCCAGCATTAG & 61 & (GT)13 \\
\hline 26 & Prb9 & ТТСТТСТССТТСТТСАТСТТССТСС & ACAACGTTGATCCCAAAACCTAAG & 62.7 & $(\mathrm{AC}) 9$ \\
\hline 27 & Prb10 & TTTTGGTGGATTTGATAGAGCC & GAGTGGGGTCAAGAAAGAACAG & 56.4 & (TCA) 5 \\
\hline 28 & Prsc1 & AATGGAGTTTGTTTGTGTCTGTGG & ATTACGGATACATCGAGCCTTCTT & 56.5 & $(\mathrm{AC}) 9(\mathrm{CT}) 5$ \\
\hline 29 & $\operatorname{Prsc} 2$ & GCGGAATTCCAAACGACAA & ACAGCAACACCCTCACTCTCAA & 64.7 & $(\mathrm{AC}) 9$ \\
\hline 30 & Prsc3 & CCACAAGCACACGCACACTCAGAC & CCAGCACTAGACTTCGCCACCAAC & 64.7 & $(\mathrm{CA}) 6$ \\
\hline 31 & sc4 & CAAAATCCAACAAATAAACACACC & GGCGGATTCTTGGCTCTCT & 63.9 & (CAA)2(GA)4 \\
\hline 32 & $\operatorname{Prsc} 5$ & CGCGTTAAGTCTGCCTTGCTTT & CTCATGGTATTTCCCTTGTCGTCC & 59 & $(\mathrm{GT}) 8$ \\
\hline 33 & Prsc6 & CGAGCGGCGAAAAATGATAAA & GCTGCTTCCCATAATCCTCTCCT & 63.9 & $(\mathrm{GT}) 8$ \\
\hline 34 & $\operatorname{Prsc} 7$ & AGGGATTTAATCTCTTTGGTGTAG & ACAAGCTGGAAAGAGTCGCA & 59 & (TG) $8(\mathrm{GTGG}) 2(\mathrm{GT}) 5$ \\
\hline 35 & $\operatorname{Prsc} 8$ & AGTGACGTGAACACGCTGAGG & TGCTGATGTGTGTGGTTTTGAGAT & 62.7 & (TG) 10 \\
\hline 36 & $\operatorname{Prsc} 9$ & TCAGACTCCCGTGAACCAG & CGCACTCGAGCAGCATCT & 59 & (TG)9 \\
\hline 37 & $\operatorname{Prsc} 10$ & AACGCAACGGCCGCAACTAT & ACAAAACGCTCGAATACTGGGGG & 56.5 & $(\mathrm{CA}) 7(\mathrm{CT}) 7$ \\
\hline 38 & Prsc11 & CCCGGCAACTCAAATCAACTTCATA & GTCTAATTCTATTGGTGGGCTCTCTGG & 62.7 & $(\mathrm{AC}) 11$ \\
\hline 39 & Prsc12 & GGGGTGCATGTTGGGGATTG & TTTGGCCGGATTAAAACAGAGCA & 59 & (GT) 10 \\
\hline 40 & Prsc13 & CTTCACCATCACCGATTTCCCTT & GCAACGAAGCAGCTGAAGAACAC & 62.7 & $(\mathrm{CTT}) 5$ \\
\hline
\end{tabular}

Note. N, number of the primer, in which species and references of SSR loci are as follow: 1-11 P. alba (Torales et al., 2013); 12-17 P. chilensis and P. flexuosa (Mottura et al., 2005); 18-40 P. rubriflora and P. ruscifolia (Alves et al., 2014).

TM is melting temperature in ${ }^{\circ} \mathrm{C}$.

\section{Copyrights}

Copyright for this article is retained by the author(s), with first publication rights granted to the journal.

This is an open-access article distributed under the terms and conditions of the Creative Commons Attribution license (http://creativecommons.org/licenses/by/4.0/). 